
\title{
25 Research Square \\ Benefits and Barriers Associated with Intention to Participate in Injury Prevention Programs in ROTC Cadets
}

Emily Gabriel ( $\sim$ Gabriel_eh@mercer.edu )

Mercer University https://orcid.org/0000-0002-1274-0634

Cameron Powden

University of Indianapolis

\section{Research}

Keywords: Attitudes, Lower Extremity Injury, ROTC Cadets, Injury Prevention

Posted Date: September 29th, 2020

DOI: https://doi.org/10.21203/rs.3.rs-84399/v1

License: (c) (i) This work is licensed under a Creative Commons Attribution 4.0 International License.

Read Full License 


\section{Abstract}

Background: There is a lack of participation in Exercise-Related Injury Prevention Programs (ERIPPs) within Reserve Officer Training Corps (ROTC) which limits the effectiveness. Identification of factors which may influence participation in ERIPPs within ROTC cadets is an important first step in improving adoption and adherence rates. Therefore, the purpose of the study was to identify factors associated with intention to participate in an ERIPP within ROTC cadets.

Methods: The study design was cross-sectional where a paper survey was distributed in spring 2019. Twenty-eight $(M / F=23 / 5$; Age=20.68 \pm 2.02 years; Height=175.78 $\pm 8.95 \mathrm{~cm}$; Mass=75.30 $\pm 11.10 \mathrm{~kg})$ ROTC cadets volunteered to participate in this study. Participants completed the Health Belief Model Scale (HBMS) and Theory of Planned Behavior Scale (TPBS) to assess attitudes towards participation in ERIPPs. A backwards multiple linear regression was used to determine if associations between attitudes towards ERIPP participation and intention to participate existed. Partial eta squared was calculated for each significant variable to determine the strength of the association and alpha was set at $P \leq 0.05$ for all analyses.

Results: Perceived benefits $\left(B=4.364, \nabla^{2}=0.68, p<0.001\right)$ had a positive and large association with intention to participate while perceived barriers $\left(B=-2.43, \otimes^{2}=0.40, p<0.001\right)$ had a negative and large association with intention to participate. There were no other statistically significant associations $(p>0.05)$.

Conclusion: Perceived benefits and barriers were significantly associated with intention to participate in ERIPPs within ROTC cadets. Implementation strategies for ERIPPs may need to focus on the benefits and barriers of participating in an ERIPP to increase adoption and adherence.

\section{Background}

Lower extremity injuries are common in the physically active population including those participating in the military (1-3). Military personnel suffer musculoskeletal injuries in the knee and ankle very similarly to individuals who participate in physical and sporting activities (4). From 1998 to 2006, over 423,000 service members sustained an ankle sprain injury at a rate of 34.95 per 1,000 person-years (1). In comparison, from 1998-2004, 27,117 ankle sprains occurred within collegiate athletes at a rate of 0.83 per 1,000 exposures (5). Additionally, from 1998-2003 over 70,000 members of the military sustained an injury to the anterior cruciate ligament of the knee (2) while 4,800 injuries occurred within collegiate athletes at a rate of 0.15 per 1,000 exposures between 1998-2004 (5). The consequences of these injuries are significant in the short- and long-term. Some of the short-term consequences include pain, loss of function, and missed duty (6). In the long-term, there is an increased likelihood for the early development of osteoarthritis (7) and decreased health-related quality of life (8). Focus has been shifted to prevention of these injuries to avoid the negative consequences associated with them. 
In 2003, a military based group was established to investigate different methods of injury prevention and make recommendations for military personnel (9). They determined the four critical components to effective injury prevention were education, leader support, surveillance, and research to support the effectiveness. Furthermore, six methods of injury prevention were found that met all criteria and were recommended to all portions of the military. One of the six methods was exercise-related injury prevention programs (ERIPPs) (9). ERIPPs are designed to prevent musculoskeletal injuries using balance, strength, range of motion, and agility exercises. Several ERIPPs have demonstrated efficacy to reduce the risk of lower extremity injuries and improve functional performance of participants in sporting and military populations (10-12). However, one of the major limitations of the effectiveness of these programs is the adoption and subsequent adherence to completing the exercises as prescribed by users $(13,14)$.

One major step in starting to improve adherence rates is to gain a better understanding of the reasons behind the lack of adoption and adherence. Several studies have begun to use social and behavioral theoretical models and frameworks to better understand the uptake of preventative health behaviors (1518). The two most commonly used theories are the Health Belief Model (HBM) and Theory of Planned Behavior (TPB). The HBM contains six theoretical constructs (perceived susceptibility, perceived severity, perceived benefits, perceived barriers, cues to action, self-efficacy) that are thought to directly predict participation in a preventative health behavior (19). The TPB contains three theoretical constructs (attitudes, perceived subjective norms, perceived behavioral control) which are thought to indirectly predict participation in a preventative health behavior through intention to participate (20). There is a lack of current literature investigating attitudes towards participating in ERIPPs within military personnel and specifically ROTC cadets. Identification of the most influential factors could enhance the development of implementation strategies for ERIPPs within this population. Therefore, the purpose of this study was to identify factors associated with intention to participate in an ERIPP within Reserve Officer Training Corps (ROTC) cadets.

\section{Methods}

A cross-sectional research design was implemented which involved participants completing paper surveys on one occasion in spring 2018. Participants completed a demographic questionnaire, Health Belief Model Scale (HBMS) (21) and Theory of Planned Behavior Scale (TPBS) (21). This study was approved by the Institutional Review Board.

Participants were recruited during ROTC courses at a single university. Twenty-eight ROTC cadets volunteered to participate in this study during the spring semester (Table 1). Participants were included if they were over the age of 18 and reported being physically active. Physically active was defined as participating in a moderate level of physical activity for at least 90 minutes per week. The primary investigator explained the study and went over the consent forms with the participants. Once the participant provided written informed consent, survey packets were distributed. 
Table 1

Participant Demographics

\begin{tabular}{|ll|}
\hline Variable & Mean \pm SD \\
\hline Gender (M/F) & $23 / 5$ \\
\hline Age (years) & $20.68 \pm 2.02$ \\
\hline Height (cm) & $175.78 \pm 8.95$ \\
\hline Mass (kg) & $75.30 \pm 11.10$ \\
\hline Previous Exposure to ERIPP $(\mathrm{Y} / \mathrm{N})$ & $16 / 12$ \\
\hline Previous History of Injury $(\mathrm{Y} / \mathrm{N})$ & $25 / 2$ \\
\hline
\end{tabular}

The HBMS was developed in a prior study (22) and an exploratory factor analysis confirmed the psychometric properties of the HBMS with all nine subscales having acceptable internal consistency values (Cronbach's alpha $>0.80)(21)$. The finalized version of the HBMS contained nine subscales (perceived susceptibility, perceived benefits, general health cues, perceived barriers, perceived consequences, fear of injury, community led self-efficacy, individual self-efficacy, and external health cues) comprised of a total of 39 items to assess attitudes towards ERIPP participation. The response choices ranged along a 7-point Likert scale from strongly agree to strongly disagree. Positive scores indicated positive attitudes for all subscales except for perceived barriers where a positive score meant they perceived more barriers.

The TPBS was developed in another study (22) to assess attitudes towards participation in ERIPPs. An exploratory factor analysis confirmed the psychometric properties of the TPBS with all five subscales having acceptable internal consistency values (Cronbach's alpha $>0.77)(21)$. The finalized version of the TPBS contained five subscales (perceived benefits, perceived social norms, perceived barriers, and perceived social influence, intention to participate) derived from a total of 19 items used to assess attitudes towards ERIPP participation. The response choices ranged along a 7-point Likert scale from strongly agree to strongly disagree. Positive scores indicated positive attitudes for all subscales except perceived barriers where a positive score would mean they perceived more barriers.

Scale data was scanned using Remark Office OMR (Gravic Inc, Version 10.3; Malvern, PA) and entered into a spreadsheet. Participants who were missing more than $10 \%$ of the scale data were excluded from analysis. When participants were missing less than $10 \%$ of scale data, multiple imputation was used to estimate missing data points (SPSS Version 25). The independent variables were the subscales of the HBMS and TPBS and the dependent variable was intention to participate in an ERIPP. The intention to participate variable was calculated using total scores of the intention subscale of the TPBS. Total scores and associated median and interquartile ranges were calculated for each of the HBMS and TPBS subscales. Mann-Whitney $U$ tests were used to detect differences in intention to participate in ERIPPs based on gender (Male/Female), previous exposure to ERIPP, and previous history of injury. In instances 
where intention was different based on a particular demographic variable, the variable was included within the regression model. A backwards multiple linear regression was used to determine if significant associations between the subscales of the TPBS and intention to participate in an ERIPP existed. Partial eta squared was calculated for each significant variable to determine the strength of the association (small $=0.06>\nabla^{2} \geq 0.01$, moderate $=0.14>\square^{2} \geq 0.07$, or large $=\mathbb{Q}^{2} \geq 0.15$ ) (23). Alpha was set at $P \leq 0.05$ for all analyses which were completed in fall 2019.

\section{Results}

There were no statistically significant differences in intention to participate in an ERIPP (median $=7.50$, $I Q R=6.75)$ based on demographic variables $(P>0.05)$. There was a statistically significant association between the subscales of the TPBS and intention to participate in an $\operatorname{ERIPP}\left(R^{2}(4,27)=0.80, p<0.001\right)$. Perceived benefits $\left(B=4.364, \mathbb{Q}^{2}=0.68, p<0.001\right)$ had a positive and large association with intention to participate while perceived barriers $\left(B=-2.43, \otimes^{2}=0.40, p<0.001\right)$ had a negative and large association with intention to participate (Table 2$)$. There were no other statistically significant associations $(p>0.05)$.

Table 2

Associations Between Subscales of HBMS, TPBS, and Intention

\begin{tabular}{|lllll|}
\hline Subscale & Median (IQR) & Beta & P-Value & Partial Eta Squared \\
\hline HBMS Barriers & $-1.00(7.00)$ & 1.10 & 0.18 & 0.15 \\
\hline HBMS Benefits & $5.00(11.00)$ & -1.27 & 0.31 & 0.09 \\
\hline HBMS Perceived Consequences & $1.00(6.00)$ & 1.03 & 0.34 & 0.08 \\
\hline HBMS Community Led Self-Efficacy & $6.00(5.00)$ & -1.34 & 0.12 & 0.19 \\
\hline HBMS External Health Cues & $0.00(4.00)$ & -0.27 & 0.77 & 0.01 \\
\hline HBMS Fear of Injury & $0.00(3.00)$ & -0.89 & 0.32 & 0.08 \\
\hline HBMS General Health Cues & $11.00(8.00)$ & 1.60 & 0.14 & 0.18 \\
\hline HBMS Individual Self-Efficacy & $-1.00(6.00)$ & -0.94 & 0.26 & 0.11 \\
\hline HBMS Perceived Susceptibility & $4.00(4.00)$ & -0.17 & 0.84 & 0.004 \\
\hline TPBS Barriers & $0.00(4.00)$ & -3.51 & 0.003 & 0.54 \\
\hline TPBS Benefits & $7.00(11.00)$ & 5.17 & 0.003 & 0.53 \\
\hline TPBS Social Influence & $7.00(6.00)$ & 2.22 & 0.08 & 0.23 \\
\hline TPBS Social Norms & $8.00(7.00)$ & -1.60 & 0.23 & 0.12 \\
\hline HBMS = Health Belief Model Scale; TPBS = Theory of Planned Behavior Scale \\
\hline
\end{tabular}




\section{Discussion}

The primary findings of this study were the significant associations between perceived benefits and barriers and intention to participate in an ERIPP in ROTC cadets. Additionally, it is important to note that social influence was trending towards statistical significance and had a large association with intention to participate in an ERIPP $\left(B=2.22, \otimes^{2}=0.23, p=0.08\right)$. These results indicate ROTC cadets value benefits of ERIPP participation, barriers to participate in ERIPPs, and social influences.

The two factors most associated with intention to participate in ERIPPs were perceived benefits of participation and perceived barriers to participation. Perceived benefits of participation include anything that an individual sees as gaining from their participation in an ERIPP such as reducing lower extremity injury rate, improving functional performance, and increasing knowledge of lower extremity injuries and ERIPPs. Perceived barriers include anything the individual sees as a barrier to their participation in an ERIPP. As cadets indicated that they perceived more benefits of participation and reduced challenges to their participation they were more likely to indicate enhanced levels of intention to participate in an ERIPP. These results align well with the results of a study (15) which investigated attitudes towards participation in ERIPPs within female netball players. There was a significant association between the attitudes subscale, comprised of questions related to barriers and benefits of participation, and intention to participate (15). There are multiple benefits to participating in ERIPPs within military personnel including reduction in the risk of lower extremity injury $(24)$ and improvements in functional performance $(11,25)$. Some of the proposed barriers to participation in ERIPPs have been time, availability of equipment, location of the program, and knowledge on how to perform the exercises $(17,26)$. Benefits to participation and strategies to overcome barriers may be influential to ROTC cadets when choosing to adopt ERIPPs.

The association between social influence and intention to participate was trending towards significance and was associated with a large partial eta squared effect size. The social influence subscale focuses on the influence of peer participation in an ERIPP and the importance of data to support the effectiveness of the ERIPP to improve athletic performance. Some literature has suggested that ERIPPs can not only reduce the risk of injury, but also lead to improvements in functional performance $(11,25)$. Specifically, one study indicated improvements following participation in the Dynamic Integrated Movement Enhancement program in jump landing technique (11) while another found improvements in the Army Physical Fitness Test including the 2 mile run, push-up, and sit-up performance (25). However, it is unlikely that ERIPP participants are aware of the benefits of participation specific to improvements in performance. These specific benefits could be highly motivating as ROTC cadets have requirements to pass the Army Physical Fitness Test, which requires a significant amount of physical performance. Additionally, the importance of group setting is already a factor that is instrumental in most military activities (27). The information gained in this study further supports the need for the ERIPP to be a part of normal physical fitness that is completed as a group rather than something the cadet is expected to do individually. The introduction of the specific data that shows improvements in physical performance after 
participation in an ERIPP and including the ERIPP in regularly scheduled group physical fitness sessions may encourage ROTC cadets to participate.

There were several subscales from the HBMS and TPBS that were not significantly associated with intention to participate. A few of the subscales with a lack of association with intention were HBMS perceived susceptibility, HBMS fear of injury, and HBMS perceived consequences. The participants in this study were young, healthy individuals and therefore may have not perceived susceptibility to injury, fear of injury, and consequences because most of them had probably not suffered a significant injury in the past. Although most of the participants had experienced an injury in the past, only $14 \%$ had an injury they classified as "severe". This assortation is supported by the literature that indicates that this population reports relatively low levels of perceived probability and worry/concern of injury as well as confidence in their ability to avoid injury (28). Additionally, soldiers have indicated that there is a lack of injury education in the military which could lead to a lack of realization of susceptibility and consequences of injury (29). There is a need to further investigate these variables and their importance in relation to participation in ERIPPs in other populations.

The results of this study indicate implementation plans for ERIPPs within ROTC cadets should place a focus on benefits, barriers, and social influence. Participants could be educated on the benefits of participating in ERIPPs including the reduction in lower extremity injuries and improvements in functional performance. Additionally, educational information could be provided on common barriers to participating and strategies to overcome those barriers. Lastly, social influence could be targeted by providing a group setting for the cadets to participate in. Including focus on these factors within the implementation plan for ERIPPs may lead to increased adoption and adherence of these programs. Therefore, future research is needed to determine the effectiveness of an intervention which targets these factors to improve adherence rates of ERIPPs.

There were several limitations associated with this study. Intention to participate in an ERIPP was used as the dependent variable for the regression analysis. There is currently a lack of data to suggest whether intention to participate is directly related to actual participation within users of the program. There is some evidence to suggest that intention to implement ERIPPs is not associated with actual implementation in coaches (30). The sample size for the study was limited and only contained ROTC cadets from one university. As a result, the findings of this study may not be generalized to other military personnel. Participation in an ERIPP is a multifactorial issue. For the purposes of this study, only the attitudes of the user were taken into consideration. It is likely the attitudes towards injury prevention of the leaders are an important factor and must be investigated through future research.

\section{Conclusion}

Benefits and barriers were significantly associated with intention to participate in ERIPPs within ROTC cadets. Implementation strategies should focus on presenting the benefits and barriers of ERIPP 
participation to the users. Future research is necessary to determine if interventions focused on benefits and barriers will lead to actual improvements in participation.

\section{Abbreviations}

ERIPP $=$ Exercise-Related Injury Prevention Program

HBM= Health Belief Model

HBMS = Health Belief Model Scale

ROTC= Reserve Officer Training Corps

TPB= Theory of Planned Behavior

TPBS= Theory of Planned Behavior Scale

\section{Declarations}

\section{Ethics approval and consent to participate}

Approval for this study was provided by the Mercer University Institutional Review Board. Participants provided written informed consent prior to participation.

\section{Consent for publication}

Not applicable

\section{Availability of data and materials}

The datasets used and/or analyzed during the current study are available from the corresponding author on reasonable request.

\section{Competing interests}

The authors declare that they have no competing interests.

\section{Funding}

Funding for this study was provided by the College of Health Professions Research Grant from Mercer University.

\section{Authors' contributions}

Both authors developed the idea behind the study and developed the design of the study. EG analyzed all of the data associated with this study. Both authors contributed to the writing of this manuscript and 
approved the finalized version.

\section{Acknowledgements}

Not applicable

\section{References}

1. Cameron $\mathrm{KL}, \mathrm{O}$ wens $\mathrm{BD}$, DeBerardino TM. Incidence of ankle sprains among active-duty members of the United States Armed Services from 1998 through 2006. J Athl Train. 2010;45(1):29-38 10p.

2. Owens BD, Mountcastle SB, Dunn WR, DeBerardino TM, Taylor DC. Incidence of Anterior Cruciate Ligament Injury among Active Duty U.S. Military Servicemen and Servicewomen. Mil Med. 2007;172(1):90-1.

3. Heir T. Musculoskeletal Injuries in Officer Training: One-Year Follow-Up. Mil Med. 1998;163(4):229-33.

4. Lauder TD, Baker SP, Smith GS, Lincoln AE. Sports and physical training injury hospitalizations in the Army. Am J Prev Med. 2000;18(3, Supplement 1):118-28.

5. Hootman JM, Dick R, Agel J. Epidemiology of collegiate injuries for 15 sports: summary and recommendations for injury prevention initiatives. J Athl Train. 2007;42(2):311-9.

6. Cameron KL, Owens BD. The Burden and Management of Sports-Related Musculoskeletal Injuries and Conditions Within the US Military. Clin Sports Med. 2014;33(4):573-89.

7. Cameron KL, Hsiao MS, Owens BD, Burks R, Svoboda SJ. Incidence of physician-diagnosed osteoarthritis among active duty United States military service members. Arthritis Rheum. 2011;63(10):2974-82.

8. Houston MN, Van Lunen BL, Hoch MC. Health-Related Quality of Life in Individuals With Chronic Ankle Instability. J Athl Train. 2014;49(6):758-63.

9. Bullock SH, Jones BH, Gilchrist J, Marshall SW. Prevention of Physical Training-Related Injuries: Recommendations for the Military and Other Active Populations Based on Expedited Systematic Reviews. Am J Prev Med. 2010;38(1):S156-S81.

10. Distefano LJ, Distefano MJ, Frank BS, Clark MA, Padua DA. Comparison of integrated and isolated training on performance measures and neuromuscular control. J Strength Cond Res. 2013;27(4):1083-90.

11. DiStefano LJ, Marshall SW, Padua DA, Peck KY, Beutler Al, de la Motte SJ, et al. The Effects of an Injury Prevention Program on Landing Biomechanics Over Time. Am J Sports Med. 2016;44(3):76776.

12. Root $\mathrm{H}$, Trojian T, Martinez J, Kraemer W, DiStefano LJ. Landing Technique and Performance in Youth Athletes After a Single Injury-Prevention Program Session. J Athl Train. 2015;50(11):1149-57.

13. Steffen K, Emery CA, Romiti M, Kang J, Bizzini M, Dvorak J, et al. High adherence to a neuromuscular injury prevention programme (FIFA 11+) improves functional balance and reduces injury risk in 
Canadian youth female football players: a cluster randomised trial. Br J Sports Med. 2013;47(12):794.

14. Sugimoto D, Myer GD, Bush HM, Klugman MF, McKeon JMM, Hewett TE. Compliance With Neuromuscular Training and Anterior Cruciate Ligament Injury Risk Reduction in Female Athletes: A Meta-Analysis. J Athl Train. 2012;47(6):714-23

15. White PE, Ullah S, Donaldson A, Otago L, Saunders N, Romiti M, et al. Encouraging junior community netball players to learn correct safe landing technique. J Sci Med Sport. 2012;15(1):19-24.

16. Finch CF, White P, Twomey D, Ullah S. Implementing an exercise-training programme to prevent lowerlimb injuries: considerations for the development of a randomised controlled trial intervention delivery plan. Br J Sports Med. 2011;45(10):791-6 6p.

17. O'Brien J, Finch, M, Finch, C. Injury Prevention Exercise Programs for Professional Soccer: Understanding the Perceptions of the End-Users. Clin J Sport Med. 2016;0:1-9.

18. Finch CF, Doyle TLA, Dempsey AR, Elliott BC, Twomey DM, White PE, et al. What do community football players think about different exercise-training programmes? Implications for the delivery of lower limb injury prevention programmes. Br J Sports Med. 2014;48(8):702-7 6p.

19. Rosenstock IM, Strecher VJ, Becker MH. Social learning theory and the health belief model. Health Educ Q. 1988;15(2):175-83.

20. Ajzen I. From intentions to actions: A theory of planned behavior. In: Beckmann JKaJ, editor. Action Control: From Cognition to Behavior. Heidelberg, Germany: Springer-Verlag; 1985. p. 11-39.

21. Gabriel EH, Hoch MC, Cramer RJ. Health Belief Model Scale and Theory of Planned Behavior Scale to assess attitudes and perceptions of injury prevention program participation: An exploratory factor analysis. J Sci Med Sport. 2019;22(5):544-9.

22. Gabriel E HM, Cramer R. The Development of the Theory of Planned Behavior and Health Belief Model Scales: Assessing Behavioral Determinants of Exercise-Related Injury Prevention Program Participation. Athl Train Sports Health Care. 2018; 11(3): 113-123.

23. Cohen J. Statistical power analysis for the behavioral sciences: Academic press; 2013.

24. Carow SD, Haniuk EM, Cameron KL, Padua DA, Marshall SW, DiStefano LJ, et al. Risk of lower extremity injury in a military cadet population after a supervised injury-prevention program. J Athl Train. 2016;51(11):905-18.

25. Peck KY, DiStefano LJ, Marshall SW, Padua DA, Beutler Al, Sarah J, et al. Effect of a lower extremity preventive training program on physical performance scores in military recruits. J Strength Cond Res. 2017;31(11):3146-57.

26. Saunders N, Otago L, Romiti M, Donaldson A, White P, Finch C. Coaches' perspectives on implementing an evidence-informed injury prevention programme in junior community netball. $\mathrm{Br} \mathrm{J}$ Sports Med. 2010;44(15):1128-32.

27. Ahronson A, Cameron JE. The nature and consequences of group cohesion in a military sample. Mil Psychol. 2007;19(1):9-25. 
28. Short SE, Reuter J, Brandt J, Short MW, Kontos AP. The relationships among three components of perceived risk of injury, previous injuries and gender in contact sport athletes. Athl Insight. 2004;6(3):78-85.

29. Hauschild VD, Schuh A, Jones BH. What soldiers know and want to know about preventing injuries: a needs survey regarding a key threat to readiness. US Army Med Dep J. 2016;2016:10-9.

30. Frank BS, Register-Mihalik J, Padua DA. High levels of coach intent to integrate a ACL injury prevention program into training does not translate to effective implementation. J Sci Med Sport. 2015;18(4):400-6. 